\title{
A dedicated Turners clinic improves adherence to UK recommended best practice and is well liked by patients
}

\author{
Munday J, Siva A, Thomas H, Cross L, Evans M, Page K, Karathanasi E, Albon L.
} Academic Department of Diabetes \& Endocrinology, Queen Alexandra Hospital, Portsmouth

Background

Prior to 2014 Portsmouth patients

with Turners syndrome (TS) were

seen in a variety of endocrine

clinics. Any screening

investigations required e.g.

cardiac echo \& audiology

necessitated further

appointments on different days.

The Turners Syndrome Support

Society (TSSS) recommend that

ladies should be under the care of

a specialist multi-disciplinary TS

clinic, equipped to manage the

specific medical problems

associated with the syndrome.
Innovation

Portsmouth Endocrine Department

established a dedicated Turners MDT clinic

staffed by Consultant Endocrinologist \&

nurse specialist. Liaison with cardiology \&

audiology led to provision of same day

echocardiography and audiology tests. All

patients arrive together with the first 30

minutes dedicated to discussing a relevant

topic over coffee. Subsequently patients are

seen by the nurse specialist then consultant.

Throughout the morning they go to different

departments to have their screening tests,

returning to the endocrine department to talk

with the other ladies between consultations.

\section{Audit}

We reviewed the notes of all patients with TS registered on our database. We compared our compliance with recommended monitoring pre and post establishment of the dedicated clinic.

A Patient satisfaction survey was sent to all participants Repeated non attenders were excluded.

\begin{tabular}{|l|l|l|}
\hline Screening Test & $\begin{array}{l}\text { Before joint clinic } \\
\%\end{array}$ & $\begin{array}{l}\text { After joint clinic } \\
\%\end{array}$ \\
\hline $\begin{array}{l}\text { Annual blood } \\
\text { tests }\end{array}$ & 65 & 100 \\
\hline Echocardiography & 65 & 100 \\
\hline Audiology test & 50 & 90 \\
\hline DEXA Scan & 35 & 100 \\
\hline $\begin{array}{l}\text { Thyroid } \\
\text { autoantibodies }\end{array}$ & 20 & 100 \\
\hline $\begin{array}{l}\text { Coeliac } \\
\text { Antibodies }\end{array}$ & 35 & \\
\hline
\end{tabular}

\section{Results}

There was a marked improvement seen in adherence to

recommended monitoring as per

the TSSS checklist after

establishment of the dedicated clinic. Satisfaction survey results were overwhelmingly positive. Women appreciated having all investigations on the same day, and enjoyed meeting and talking to others similarly affected
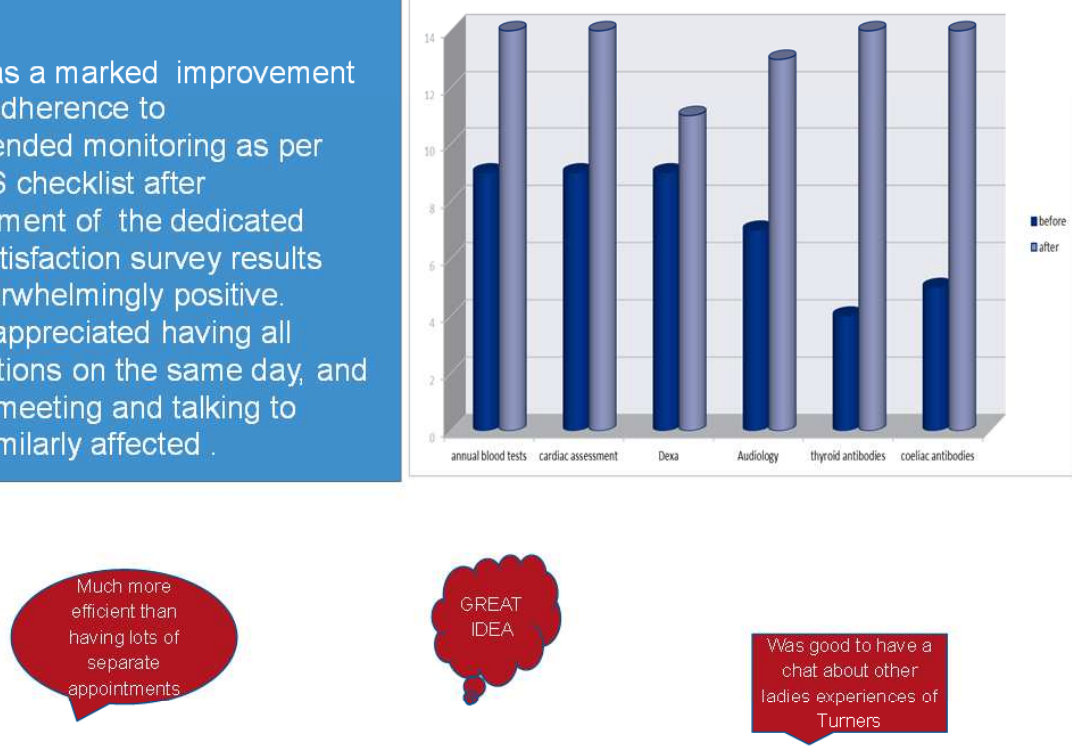

\section{Future plans}

Our cohort size suggests we are not seeing all affected women in our catchment area. The joint clinic has been advertised to local GPs raising awareness of TS and the recommended screening schedule. Additionally, we have recognised the frequency of abnormal liver function tests in this group, leading to a Consultant Hepatologist recently joining the team providing same day fibroscans and review.
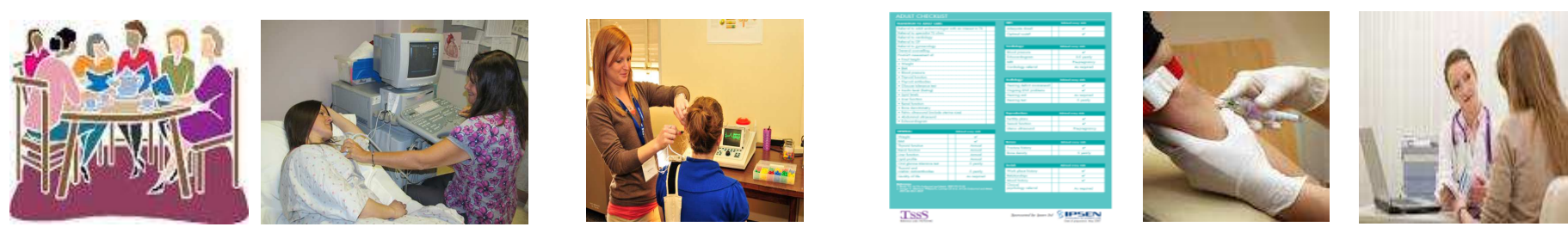